\title{
GOZOS Y DIFICULTADES DE LA VIDA CONSAGRADA EN EL MUNDO DE HOY
}

DOI: https://doi.org/10.52039/seminarios.v61i213.186

MANUEL SÁNCHEZ MONGE*

Creo que para comenzar debo unirme al agradecimiento que Benedicto XVI expresó a los consagrados: «A vosotros, queridos consagrados y consagradas, deseo expresaros mi sincero agradecimiento por todo lo que hacéis en la Iglesia y con la Iglesia a favor de la evangelización y del hombre. Trabajáis en las múltiples actividades de las parroquias, en la catequesis y la formación cristiana de los niños, de los jóvenes y de los adultos, desempeñáis un papel importante en el campo de la enseñanza y, con las múltiples obras sociales que lleváis entre manos, salís al encuentro de los hermanos más necesitados (niños, discapacitados, ancianos, enfermos...) con el amor mismo de Dios. Pienso también en el testimonio, a veces arriesgado, de vida evangélica en las misiones, en circunstancias a menudo difíciles. En todo momento manifestáis vuestra pasión por Cristo y por la humanidad ${ }^{1}$. Por otra parte, el amor a la Vida Consagrada no le impidió al papa Benedicto denunciar muy incisivamente los peligros que la acechan en la actualidad.

Después del Concilio Vaticano II, la Vida Consagrada ha entrado en un proceso de renovación, que afecta a su propia identidad (forma de vida, compromisos, presencias) y sobre todo a su misión en la Iglesia y en el mundo. Un periodo delicado y duro, no exento de dificultades que todavía perduran hoy.

\section{Dificultades de la Vida Consagrada EN EL MUNDO DE HOY}

\section{Un tiempo de dificultades para los consagrados}

La Vida Consagrada es una forma de vida religiosa que, por su especial intensidad y su carácter eclesial, se vuelve mucho más sensible al secularismo o a la crisis de relevancia que afecta a las propuestas religiosas hoy.

a) El secularismo impregna todos los ámbitos de la sociedad actual. Y amenaza con desdibujar la esencia de la Vida Consagrada, con desnaturalizar lo

* Manuel Sánchez Monge es actualmente Obispo de la diócesis de Mondoñedo-Ferrol. Miembro de la Comisión Episcopal para la Vida Consagrada.

1. Benedicto XVI a la Asamblea de Superiores Mayores, 26 de noviembre de 2010. 
propio de la consagración y su expresión externa. Hemos de darnos cuenta de que estamos asistiendo a un retroceso de la dimensión religiosa, en la que las legislaciones de los Estados se alejan cada vez más de los principios cristianos. El secularismo, con lo que conlleva por sí mismo, el relativismo moral, la dificultad de conjugar la libertad y la autonomía personal con la vida comunitaria y las decisiones de los gobernantes, la fidelidad a las opciones vitales realizadas, situaciones de sincretismo religioso, son algunos de los principales retos que los consagrados han de tener presente para no caer en ellos y perder su identidad que enriquece y vigoriza la Iglesia.

Hay que estar atentos a detectar las formas sutiles de secularización interna que se han infiltrado en el ambiente que respiramos: un lenguaje que pierde contenido religioso; una reducción del tiempo de oración y actos religiosos comunes convirtiéndolos en momentos superficiales, formales, vacíos y premurosos, privados de la participación del corazón. También una pérdida paulatina de visibilidad de la consagración; una opción por actividades sociales en detrimento de las eclesiales (catequesis, administración de sacramentos); una concepción de la misión como agentes de progreso social más que como representantes de la esperanza escatológica, dejándose sofocar por la actividad y las preocupaciones terrenas antes que por las de Dios.

b) En España -y en Europa- los consagrados son menos que en tiempos pasados y un número considerable de ellos en edad avanzada, a veces muy ancianos. El envejecimiento es una realidad que marca profundamente la vida de las Congregaciones porque frena el ritmo de vida cotidiano y reduce las posibilidades de irradiación apostólica. Pero a la hora de promover vocaciones se ha de tener en cuenta la advertencia del papa Francisco: «Bien podemos aplicar a la vida consagrada lo que escribí en la Exhortación apostólica Evangelii gaudium, citando una homilía de Benedicto XVI: «La Iglesia no crece por proselitismo, sino por atracción» (n. 14). Sí, la vida consagrada no crece cuando organizamos bellas campañas vocacionales, sino cuando los jóvenes que nos conocen se sienten atraídos por nosotros, cuando nos ven hombres y mujeres felices. Tampoco su eficacia apostólica depende de la eficiencia y el poderío de sus medios. Es vuestra vida la que debe hablar, una vida en la que se trasparenta la alegría y la belleza de vivir el Evangelio y de seguir a Cristo»².

c) Por otra parte, si el tercer milenio trae consigo mayor protagonismo de los laicos, de las asociaciones y de los movimientos eclesiales, los consagrados han de interrogarse sinceramente sobre cuál será el puesto reservado a las formas tradicionales de vida consagrada.

d) En la misma Iglesia no se tiene en la debida consideración a los consagrados. E incluso se da una cierta desconfianza hacia ellos.

2. Papa Francisco, Carta Apostólica a todos los consagrados con ocasión del Año de la Vida Consagrada, 21.11.2014, 1. 
e) Es indudable, a mayor abundamiento, que ante la progresiva crisis religiosa que asalta a gran parte de nuestra sociedad, las personas consagradas, hoy de manera particular, se ven obligadas a buscar nuevas formas de presencia y a plantearse no pocos interrogantes sobre el sentido de su identidad y de su futuro.

f) Algunas de las obras que mantenían los consagrados no responden a las condiciones objetivas que justificaron su nacimiento, la enorme inversión que requirieron y los sacrificios de tantos Hermanos para sostenerlas. No son pocos los casos en que instituciones de carácter educativo o asistencial regidas por los religiosos han sido confiadas a seglares ante la incapacidad física de los consagrados para dedicarse a dichas obras, cuya misión debe replantearse.

g) Con cierta frecuencia saltan a los titulares de la prensa personas consagradas, sobre todo en terrenos de misión, capaces de dar un testimonio heroico y de entregarse hasta el martirio. Pero los consagrados -como los demás seguidores de Jesucristo- conocen también la insidia de la mediocridad en la vida espiritual, del aburguesamiento progresivo y de la mentalidad consumista. Y, junto a todo esto, la tentación del activismo y buscar la eficacia por encima de todo. Así corren el riego de ofuscar la originalidad evangélica y de debilitar las motivaciones espirituales.

h) El triste fenómeno de los abandonos, de las salidas o crisis vocacionales, que ha afectado de alguna manera a todas las congregaciones, ha repercutido muy negativamente en la promoción vocacional y ha sido factor de desánimo y desconcierto para los consagrados que permanecen en sus Institutos.

\section{Las dificultades, un tiempo de gracia ${ }^{3}$}

Las dificultades del momento actual pueden llevar al pesimismo, al encogimiento, buscando refugio en la nostalgia de tiempos pasados y maldiciendo, de algún modo, los tiempos presentes. Por el camino de la añoranza pronto llegaremos inevitablemente a la decadencia, a la esterilidad y a la amargura. Pero también se pueden vivir tratando de ver en ellas mismas una auténtica llamada del Espíritu Santo a la conversión. Al fin y al cabo la Vida Consagrada no la inventamos nosotros. Es el Espíritu el que la crea, la recrea y la transforma; es El quien la impulsa constantemente a la fidelidad creativa. "Las dificultades -enseñaba el papa Benedicto- no deben, sin embargo, inducir al desánimo. Es preciso más bien comprometerse con nuevo ímpetu, porque la Iglesia necesita la aportación espiritual y apostólica de una vida consagrada renovada y fortalecida» ${ }^{4}$. A pesar del dolor y desorientación que producen no son el peligro más grave para la vida consagrada. El daño mayor a la vida consagrada lo produce

3. Para todo lo que sigue, cf. Congregación para los Institutos de Vida Consagrada y las Sociedades de Vida Apostólica, Caminar desde Cristo: un renovado compromiso de la vida consagrada en el Tercer Milenio, 12.

4. Juan Pablo II, Vita Consecrata [= VC], 13. 
todo aquello que contamina y destruye la fe, la vida cristiana, la radicalidad en el seguimiento de Jesucristo, debilitando su capacidad de profecía y testimonio, ocultando la belleza de su rostro 5 .

En una sociedad donde con frecuencia reina la cultura de muerte, los consagrados pueden convertirse con más fuerza en testigos y portadores de vida y esperanza para sus contemporáneos. Nuestro mundo y nuestra Iglesia necesitan personas integradas, maduras, disponibles y gozosas, sin apegos y sin miedos ni represiones tontas.

Los consejos evangélicos de castidad, pobreza y obediencia, vividos por Cristo en la plenitud de su humanidad de Hijo de Dios y abrazados por su amor, aparecen como un camino para la plena realización de la persona en oposición a la deshumanización, representan un potente antídoto a la contaminación del espíritu, de la vida, de la cultura; y una proclamación de la libertad de los hijos de Dios, de la alegría de vivir según las bienaventuranzas evangélicas. La pobreza vivida en clave de solidaridad y comunión, desde una vida modesta y sencilla que la haga creíble, es algo que desconcierta, sorprende y admira. Dependiendo únicamente de Dios, los consagrados están llamados a vivir una libertad que les impide ser esclavos de nada ni de nadie en este mundo. En este momento histórico han de prestar un poco más de atención a su ser sin vivir atenazados por los excesivos quehaceres de cada día.

La pérdida de estima por parte de algún sector de la Iglesia por la Vida Consagrada, puede vivirse como una invitación a una purificación liberadora. Los consagrados no deben buscar las alabanzas y las consideraciones humanas; su recompensa consiste en el gozo de trabajar activamente al servicio del Reino de Dios, para ser germen de vida que crece en el silencio más discreto, sin esperar otra recompensa que la que el Padre dará al final (cf. Mt 6, 6). En la llamada del Señor, en su seguimiento, amor y servicio incondicionales, encuentran su identidad que les colma de vida y les confiere plenitud de sentido. No pueden vivir para conservar estructuras, a veces tan pesadas, que les convierten en pequeños empresarios o gestores, sino para aligerarlas y ponerlas al servicio del Espíritu, que es al que en definitiva tienen que servir. En nuestra sociedad y nuestra Iglesia, los consagrados verificarán su experiencia de Dios viviendo en servicio la misericordia y la acogida del extranjero.

Si en algunos lugares las personas consagradas son pequeño rebaño porque son pocas y mayores, este hecho puede interpretarse como un signo providencial que invita a recuperar la propia tarea esencial de levadura, de fermento, de signo y de profecía. Cuanto más grande es la masa que hay que fermentar, tanto más rico de calidad deberá ser el fermento evangélico, y tanto más excelente el testimonio de vida y el servicio carismático de las personas consagradas. Utilizando el símil del automóvil se ha dicho que el problema de la Vida consagrada

5. Cf. Benedicto XVI, Homilía en la festividad de San Pedro y Pablo, Roma, 29 junio 2009. 
hoy no es de carrocería, ni de equipamiento o diseño aerodinámico..., sino de motor, de responsabilidad personal, de revisión de sistemas internos de formación para la madurez humana, cristiana y de vida consagrada. Por otra parte, los consagrados -cuando son pocos y mayores- están llamados a mostrar al mundo su fragilidad, sin caer en el exhibicionismo. Y que el mundo vea, como dice san Pablo, que la fuerza de Dios se manifiesta en la debilidad de los hombres.

La universalidad de la vocación a la santidad por parte de todos los cristianos, no perjudica a un estado particularmente apto para conseguir la perfección evangélica. Al contrario, debe ser un ulterior motivo de gozo para las personas consagradas porque están ahora más cercanas a los otros miembros del pueblo de Dios con los que comparten un camino común de seguimiento de Cristo, en una comunión más auténtica, en la emulación y en la reciprocidad, en la ayuda mutua de la comunión eclesial, sin superioridades ni inferioridades enfermizas. Al mismo tiempo, esta toma de conciencia es un llamamiento a comprender el valor del signo de la vida consagrada en relación con la santidad de todos los miembros de la Iglesia.

En definitiva los desafíos a la vida consagrada hoy pueden constituir un fuerte llamamiento a profundizar la vivencia de la propia consagración, cuyo testimonio es hoy más necesario que nunca. Es oportuno recordar cómo los santos fundadores han sabido responder con una genuina creatividad carismática a los retos y a las dificultades del propio tiempo, que seguramente no fue ni mejor ni peor que el nuestro.

\section{Gozos de LA VIDA Consagrada EN EL MUNDO DE HOY}

EI Papa Benedicto XVI señalaba en su momento tres aspectos positivos de los consagrados hoy: «la vida consagrada en los últimos años ha vuelto a ser comprendida con un espíritu más evangélico, más eclesial y más apostólico» ${ }^{6}$.

a) Los consagrados en el momento presente cuidan con esmero la devoción personal y comunitaria, y la liturgia. Potencian la dimensión espiritual con el canto, gusto estético en las celebraciones que ayuda a acercar a alejados o extraños. Se vive la oración comunitaria como un momento de gran intensidad espiritual y de trascendencia. En lugar de privatizar la oración, ésta se vuelve un momento de anuncio y de transmisión del Evangelio. Se recuperan expresiones tradicionales (rosario, adoración eucarística...) y nuevas de devoción y de espiritualidad. La vitalidad se percibe sobre todo en el modo de rezar, y se convierte en una invitación al seguimiento, a vivir una vida cuya finalidad primera es precisamente recrear un horizonte de trascendencia en un mundo muy material y secular.

6. Benedicto XVI, Discurso a las Superioras y Superiores Generales de las Congregaciones e Institutos Seculares, 22 de mayo de 2006. 
b) Los consagrados se sitúan actualmente más en los límites o las fronteras de las culturas dominantes, convirtiéndose así en formas alternativas de vida. Es decir, modelos de existencia fundados sobre otros valores distintos a los que asume la mayoría. No pretenden tanto seguir a Cristo asimilándose al contexto cultural y a los seglares, sino reivindicar y recordar la presencia de un horizonte espiritual más allá de los límites y de la aridez del paisaje secularizado de nuestra sociedad.

c) «La vida fraterna -recordaba Benedicto XVI a los consagrados- es uno de los aspectos que más buscan los jóvenes cuando se acercan a vuestra vida; es un elemento profético importante que ofrecéis en una sociedad fuertemente individualista. Conozco las dificultades que la vida comunitaria comporta. Es necesario un serio y constante discernimiento para reconocer lo que viene del Señor y lo que le es contrario. Sin el discernimiento, acompañado de la oración y de la reflexión, la vida consagrada corre el peligro de acomodarse a los criterios de este mundo: el individualismo, el consumismo, el materialismo; criterios que hacen disminuir la fraternidad y hacen perder fascinación y penetración a la misma vida consagrada» ${ }^{7}$. En muchas de nuestras comunidades de consagrados conviven personas de diversas razas, culturas y edades que constituyen una auténtica oportunidad para que se viva la catolicidad de la Iglesia y son un reto para los demás cristianos porque no es fácil la vida común de personas de culturas diferentes. Para nosotros, que experimentamos dificultades en convivir los de diversas regiones, son un testimonio interpelador y estimulante.

d) Capacidad para la movilización evangelizadora. «La misión es el modo de ser de la Iglesia y, en ella, de la vida consagrada, seguía diciendo el papa Benedicto; forma parte de vuestra identidad; os empuja a llevar el Evangelio a todos, sin límites. La misión, sostenida por una fuerte experiencia de Dios, por una robusta formación y por la vida fraterna en comunidad, es una clave para comprender y revitalizar la vida consagrada. Id, por tanto, y en fidelidad creativa haced vuestro el desafío de la nueva evangelización. Renovad vuestra presencia en los areópagos de hoy para anunciar, como hizo san Pablo en Atenas, al Dios «desconocido» ${ }^{8}$. Y el papa Francisco ha insistido de nuevo: «Los consagrados deben salir de sí mismos para ir a las periferias existenciales. Hay toda una humanidad que espera: personas que han perdido toda esperanza, familias en dificultad, niños abandonados, jóvenes sin futuro alguno, enfermos y ancianos abandonados, ricos hartos de bienes y con el corazón vacío, hombres y mujeres en busca del sentido de la vida, sedientos de lo divino... No os repleguéis en vosotros mismos -sigue pidiendo el papa Francisco-, no dejéis que las pequeñas peleas de casa os asfixien, no quedéis prisioneros de vuestros problemas. Estos

7. Benedicto XVI, A la Asamblea de Superiores Mayores, 26 de noviembre de 2010.

8. Ibid. 
se resolverán si vais fuera a ayudar a otros a resolver sus problemas y anunciar la Buena Nueva. Encontraréis la vida dando la vida, la esperanza dando esperanza, el amor amando»?.

A pesar de las dificultades, hemos de tomar nota de tres hechos significativos:

1. En primer lugar, algunas Órdenes tradicionales que han asumido un estilo más radicalmente evangélico, han acabado invirtiendo la tendencia al desgaste que sufrían y reciben nuevos miembros en nuestros días.

2. En segundo lugar, están surgiendo entre nosotros las llamadas 'nuevas formas de Vida Consagrada'. Y, superando ambigüedades y obstáculos, van logrando una cierta estabilidad y gozan de buena salud.

3. Han nacido, dentro de los llamados nuevos movimientos eclesiales, formas originales de vida muy próximas a lo que conocemos como Vida Consagrada $o$ algunos de sus miembros nutren con abundantes vocaciones monasterios y congregaciones con los que han sentido cierta afinidad o sintonía.

\section{El FUtURo de LA Vida CONSAGRADA}

El futuro de la Vida Consagrada está en manos de Dios, pero también depende de la respuesta lúcida, creativa y coherente a las llamadas que el Espíritu hace en nuestros días.

\section{Propuestas para caminar en el futuro}

Los consagrados han de lograr articular bien cuatro elementos:

a) Una relación personal, intensa y gozosa con Dios, convertido en la única razón de su vida, junto con la capacidad de iniciar a los demás en el encuentro con el Señor que sobrecoge, cautiva y entusiasma.

b) Una vida que, firmemente asentada en Dios, no sea ajena a los dolores del mundo, sino que, en medio de ellos y sin desentenderse de ellos, descubre la presencia del Dios de la esperanza y del consuelo.

c) Un estilo de vida sencillo y fraternal, que sea una alternativa al consumismo y la competitividad que genera la economía de mercado que nos envuelve.

d) El marco institucional no puede convertirse en una pesada carga y en un obstáculo de cara a la renovación. Muchas de las actividades que marcaron a varias generaciones de consagrados en los dos últimos siglos han perdido el valor y el significado que tuvieron. La Vida Consagrada ha de buscar hoy cuáles pueden ser los lugares y las obras más convenientes para estos nuevos tiempos y condiciones sociales.

9. Papa Francisco, Carta Apostólica a todos los consagrados con ocasión del Año de la Vida Consagrada, 21.11.2014, 4. 
El mismo Papa Benedicto añadía estas propuestas positivas para caminar en el futuro: «El Señor quiere hombres y mujeres libres, que no estén condicionados, capaces de abandonarlo todo para encontrar sólo en Él su todo. Se necesitan opciones valientes, a nivel personal y comunitario, que impriman una nueva disciplina a la vida de las personas consagradas y la lleven a descubrir la dimensión integral del seguimiento de Cristo. Pertenecer totalmente a Cristo quiere decir arder con su amor incandescente, quedar transformados por el esplendor de su belleza: nuestra pequeñez se le ofrece como sacrificio de suave fragancia para que se convierta en testimonio de la grandeza de su presencia para nuestro tiempo, que tanta necesidad tiene de quedar ebrio por la riqueza de su gracia. Pertenecer al Señor: esa es la misión de los hombres y mujeres que han optado por seguir a Cristo casto, pobre y obediente, para que el mundo crea y se salve. Ser totalmente de Cristo siendo una permanente confesión de fe, una inequívoca proclamación de la verdad que libera de la seducción de los falsos ídolos que deslumbran el mundo. Ser de Cristo significa mantener siempre ardiente en el corazón una llama viva de amor, alimentada continuamente por la riqueza de la fe, no sólo cuando lleva consigo la alegría interior, sino también cuando va unida a las dificultades, a la aridez, al sufrimiento. El alimento de la vida interior es la oración, íntimo coloquio del alma consagrada con el Esposo divino. Un alimento más rico todavía es la cotidiana participación en el misterio inefable de la divina Eucaristía, en la que se hace presente constantemente Cristo resucitado en la realidad de su carne».

En cada época los consagrados han sabido responder a las necesidades espirituales de sus contemporáneos. Hoy como entonces los consagrados han de responder de forma creíble a la indiferencia religiosa, a la pérdida del sentido de la trascendencia y de la esperanza escatológica. La vida de la Iglesia y la sociedad misma, tienen necesidad de personas capaces de entregarse totalmente a Dios y a los otros por amor de Dios.

Se necesita reforzar la eclesialidad de la vida consagrada. Porque es esencialmente un servicio en la Iglesia y para la Iglesia, según los propios carismas. Pero como nos recuerda el papa Francisco: «Esta Iglesia con la que debemos sentir es la casa de todos, no una capillita en la que solo cabe un grupito de personas selectas. No podemos reducir el seno de la Iglesia universal a un nido protector de nuestra mediocridad». «Veo con claridad que la Iglesia hoy necesita con mayor urgencia la capacidad de curar heridas y de dar calor a los corazones de los fieles, cercanía, proximidad. Veo a la Iglesia como un hospital de campaña tras una batalla». Los religiosos y religiosas saben mucho de curar heridas y de poner calor en los corazones.

La realidad social de nuestro tiempo no favorece la fidelidad. Basta mirar a nuestro alrededor y descubrimos la fragilidad de las decisiones tomadas, la poca duración de los compromisos adquiridos, la facilidad con que se renuncia a los proyectos, ilusiones y obligaciones asumidas. Realidades que son aplicables a 
todos los ámbitos: el del trabajo, el afectivo, el familiar, el económico... Asistimos a una constante petición de indultos de salida del Instituto y de dispensa de los votos. Hoy la fidelidad a la opción de vida tomada dura poco. Pero es precisamente sobre esta realidad donde la Vida Consagrada debe focalizar sus energías para presentarse como un ejemplo no sólo de fidelidad, sino de aquello que puede sostener las pruebas que a lo largo de la vida se presentan y que no pocas veces hace que nuestra existencia tiemble. Cristo, 'testigo fiel', es la raíz de la fidelidad de los consagrados y de todo cristiano. El primado de Cristo sobre todo es el criterio de juicio y de acción, es el principio generador de la vida consagrada. Quien tiene a Cristo vivo y actual en su corazón conocerá entonces una fidelidad que expresa la fuerza de un amor que es respuesta al Amor, un amor que no teme de ponerse y de estar firme, bajo la cruz.

La Vida Consagra ha de potenciar hoy su dimensión profética: «Espero que 'despertéis al mundo', dice el papa Francisco, porque la nota que caracteriza la vida consagrada es la profecía. Como dije a los Superiores Generales, 'la radicalidad evangélica no es sólo de los religiosos: se exige a todos. Pero los religiosos siguen al Señor de manera especial, de modo profético'. Esta es la prioridad que ahora se nos pide: Ser profetas como Jesús ha vivido en esta tierra... Un religioso nunca debe renunciar a la profecía» ${ }^{10}$. Ahora bien, nunca se debe perder de vista que «la verdadera profecía nace de Dios, de la amistad con Él, de la escucha atenta de su Palabra en las diversas circunstancias de la historia. El profeta siente arder en su corazón la pasión por la santidad de Dios $y$, tras haber acogido la palabra en el diálogo de la oración, la proclama con la vida, con los labios y con los hechos, haciéndose portavoz de Dios contra el mal y contra el pecado» ${ }^{11}$.

2. Vivir la consagración desde la fe en que la fuerza de Dios se manifiesta en la debilidad de los hombres

Incluso las debilidades e imperfecciones se convierten para los consagrados en una puerta por la que Dios entra en sus vidas. Sus contradicciones interiores y sus miedos pueden permanecer, pero ellos experimentan la presencia de Cristo y la fuerza del Espíritu Santo hasta que la oscuridad se transforma en luz. No pueden dar la impresión de que no necesitan nada ni a nadie, que tienen respuestas para todas las preguntas. La inteligencia de la fe no es solamente una repetición de respuestas, sino una búsqueda innovadora de los caminos de la fe. La actual fragilidad de la Vida Consagrada quizás sea una etapa necesaria en el camino hacia su profunda renovación. ¿Quién no se ha encontrado a lo largo de su vida con ancianos luminosos capaces de irradiar una sabiduría y un amor auténticos?

10. Papa Francisco, 29 noviembre 2013.

11. Cf. Vita Consecrata, 84. 
Hay que vivir conociendo las limitaciones de la Vida Consagrada, sin resignarse al hecho de no poderlas modificar, y, por tanto, tener el valor de dejarse tocar por una conversión permanente. Creer que la Vida Consagrada es posible en nuestro mundo significa apelar a lo mejor que se nos ha concedido vivir. Es lanzar una invitación a todos los que han entrado en la aventura de caminar con Cristo para volver a decir juntos lo que hemos vivido y las perspectivas que se han abierto en nuestras vidas. 